\title{
Superplastic forming and diffusion bonding: Progress and trends
}

\author{
Li Zhiqianga ${ }^{\mathrm{a}}$, Zhao Bing, and Chen Wei
}

AVIC BeiJing Aeronautical Manufacturing Technology Research Institute, 100024 BeiJing, China

\begin{abstract}
This paper summarized recent progress in metal superplasticity and the application of Superplastic Forming/Diffusion Bonding (SPF/DB) or SPF/Welding in typical structures. Various aerospace components such as three dimensional lattice structures made by SPF/DB have been demonstrated. In addition, some newly developed technologies, such as melt droplet spreading/thermo-mechanical forming (MDS/TMF), were also included. Finally, the future potential of SPF/DB technology was predicted.
\end{abstract}

\section{Introduction}

Superplastic forming/diffusion bonding (SPF/DB) is a technology that uses material superplasticity and diffusion to produce complex hollow or honeycomb structures in a single step. Compared with conventional forming and shaping methods, significant cost and weight savings can be achieved. Cost reductions result from material savings, reduced tooling costs, and reduced efforts due to single-step component manufacturing. Major advantages of this technology also include high design freedom, little spring-back, short lead time, etc. SPF/DB structures significantly reduce part numbers and increase structure integrety. SPF and SPF/DB have today matured to an economic manufacturing technique for complex titanium sheet structures. Typically, 10-50\% weight savings and 25-40\% cost reduction can be achieved for using an SPF/DB structure. Multi-layer hollow structures of various types can be made by this technology [1].

$\mathrm{SPF} / \mathrm{DB}$ structures made of $\mathrm{Al}, \mathrm{Ti}$ and superalloys are mainly used as aerospace components such as ducts, aircraft wing access panels, rudders, nozzles, engine casings and blades. X.H. Zhang et al. [2] initiated research on Ti-6Al-4V honeycomb and corrugated sheet using SPF/DB and components such as heat shield tile have been made. K.F. Zhang et. al. [3-5] studied Ti and Ni multi-layer structures, and the effect of electric field assisted forming on SPF/DB structures.

This paper reviewed some progress in metal superplasticity and SPF/DB technology. Some new technologies in this research field were also introduced.

\footnotetext{
${ }^{\text {a }}$ Corresponding author: author@e-mail.org
}

This is an Open Access article distributed under the terms of the Creative Commons Attribution License 4.0, which permits unrestricted use, distribution, and reproduction in any medium, provided the original work is properly cited. 


\section{MATEC Web of Conferences}

\section{Progress in metal superplastic forming}

\subsection{Metal superplasticity}

The superplastic behaviour and deformation mechanism have been studied for alloys such as Ti-6Al-4V, Ti55, TNW700, TiAl, and AlLi. This has provided valuable information for the production of hollow structure using SPF/DB process.

K. Han et. al. [6] found that hydrogenating Ti alloys can reduce temperature and increase strain rate during SPF, which provides a viable way of fulfilling low temperature and high strain rate deforming for $\mathrm{Ti}$ alloys. However, most of the research has been concentrating on compressive forming in literature. BAMTRI studied the tensile superplasticity of Ti-6Al-4V sheet at $800^{\circ} \mathrm{C} \sim 860^{\circ} \mathrm{C}$ and $1 \times 10^{-3} \mathrm{~s}^{-1}$ strain rate. Hydrogen addition increased the $\beta$ phase volume fraction and the microstructure transformed from equiaxed to duplex. Ti hydride formed when $\mathrm{H}$ content reached a certain number. Meantime, some $\mathrm{H}$ could lower the SPF peak stress and $0.32 \mathrm{wt} . \% \mathrm{H}$ caused $55 \%$ reduction of peak flow stress. $\mathrm{H}$ addition could also lower SPF temperature by $60 \sim 100{ }^{\circ} \mathrm{C}$. Ti-6Al-4V alloyed with 0.32 wt. $\%$ H reached $1190 \%$ elongation at $840^{\circ} \mathrm{C}$, which was $75 \%$ higher than the base alloy. Further research [7] has been performed at $800^{\circ} \mathrm{C} \sim 900^{\circ} \mathrm{C}$ and strain rate of $3 \times 10^{-4} \mathrm{~s}^{-1} \sim 1 \times 10^{-2} \mathrm{~s}^{-1}$. The peak stress decreased $15 \mathrm{MPa} \sim$ $33 \mathrm{MPa}$ and the $\mathrm{m}$ value (strain rate sensitivity index) increased to 0.497 . The activation energy was calculated to be $322 \mathrm{~kJ} / \mathrm{mol}$. The material exhibited best superplasticity at $840{ }^{\circ} \mathrm{C} \sim 860{ }^{\circ} \mathrm{C}$ and strain rate of $3 \times 10^{-3} \mathrm{~s}^{-1} \sim 1 \times 10^{-3} \mathrm{~s}^{-1}$. The highest elongation value was $1530 \%$. H addition of $0.11 \mathrm{wt} . \%$ softened the $\alpha / \beta$ phase, promoted dynamic recrystallization, increased the dislocation climb and reduced dislocation density. Volume fraction of $\alpha / \beta$ phase has not changed during SPF. It is believed that the appropriate volume fraction could restrain grain growth. The mechanism of superplasticity was the same for the hydrogenated material and the base material. Grain boundary sliding and grain rotation played a key role, while dislocation climb and dynamic recrystallization also contributed.

TNW700 (Ti-5.86Al-3.4Sn-5.56Zr-1.15Nb-1.6W-0.19Si) is a near- $\alpha$ Ti alloy which can be used for short time at $700{ }^{\circ} \mathrm{C}$. BAMTRI has studied the tensile superplasticity of this alloy at $890^{\circ} \mathrm{C} \sim 950{ }^{\circ} \mathrm{C}$ and strain rate of $5 \times 10^{-4} \mathrm{~s}^{-1} \sim 1 \times 10^{-2} \mathrm{~s}^{-1}$. Maximum elongation was obtained at strain rate of $5 \times 10^{-4} \mathrm{~s}^{-1}$ at all testing temperatures except $950{ }^{\circ} \mathrm{C}$. Elongation value exhibited a parabola change along with strain rate. Maximum value of $933 \%$ was obtained at $950{ }^{\circ} \mathrm{C} / 5 \times 10^{-4} \mathrm{~s}^{-1}$. Volume fraction of $\beta$ phase increased with temperature and so did the grain size. For the sample tested at $930^{\circ} \mathrm{C}$ and $950^{\circ} \mathrm{C}$, there was secondary $\alpha$ phase precipitated out in $\beta$ grains at strain rate of $1 \times 10^{-2} \mathrm{~s}^{-1}$. It is believed that the precipitates were caused by local composition change. As the strain rate decreased, the secondary $\alpha$ disappeared. The growth of $\beta$ grains has caused increased strain hardening.

Ti55 is a near a Ti alloy developed by IMR (Institute of Metal Research) of Chinese Academy of Sciences for application at $550^{\circ} \mathrm{C}$. $\mathrm{Nd}$ is added to form $\mathrm{Nd} 3 \mathrm{Sn}$ phase for grain boundary strengthening and grain refinement. B. Zhao et al. [8] has studied the superplastic behaviour of Ti55. It is observed that Ti55 exhibited best superplasticity $900{ }^{\circ} \mathrm{C} \sim 1000^{\circ} \mathrm{C}, 1.5 \times 10^{-4} \mathrm{~s}^{-1} \sim 5.0 \times 10^{-3} \mathrm{~s}^{-1}$. The highest elongation reached $540 \%$ and the $\mathrm{m}$ value was 0.46 . At low temperature, it is believed that grain boundary sliding and dislocation climb were active; while at high temperature; grain boundary sliding and diffusion were active. Deformation of $\mathrm{Nd} 3 \mathrm{Sn}$ phase was negligible during SPF. The optimal combination of temperature, time and pressure for making four-layer components by SPF/DB was found to be $940^{\circ} \mathrm{C} / 2.5 \mathrm{~h} / 2 \mathrm{MPa}$.

B. Zhao et. al. studied the SPF/DB behaviour of a Ti-based intermetallic (Ti-48Al-2Cr-2Nb) [8]. The testing temperature was $1050^{\circ} \mathrm{C} \sim 1175^{\circ} \mathrm{C}$ and strain rate was $1.2 \times 10^{-5} \mathrm{~s}^{-1} \sim 8.3 \times 10^{-5} \mathrm{~s}^{-1}$. Maximum elongation was $300 \%$ at $1100^{\circ} \mathrm{C} / 8.3 \times 10^{-5} \mathrm{~s}^{-1}$. A DB experiment was performed at $900{ }^{\circ} \mathrm{C} \sim 1100{ }^{\circ} \mathrm{C}, 0.5 \mathrm{~h} \sim 2 \mathrm{~h}, 10 \mathrm{MPa}$. There was no interface defect found in DB area. At the optimal conditions, a two-layer SPF/DB component made is fabricated.

Al-Li alloys have attracted much attention in recent years because of their low density, high specific strength and good weldability. Replacing conventional Al with Al-Li for aircraft components could have 
Table 1. Room-temperature tensile properties of 1420 Al-Li alloy.

\begin{tabular}{|c|c|c|c|}
\hline & $\sigma_{b}, \mathrm{MPa}$ & $\sigma_{0.2}, \mathrm{MPa}$ & Elongation, \% \\
\hline As-received & 400 & 259 & 19.3 \\
\hline After $460^{\circ} \mathrm{SPF}$ & 372 & 177 & 20 \\
\hline
\end{tabular}

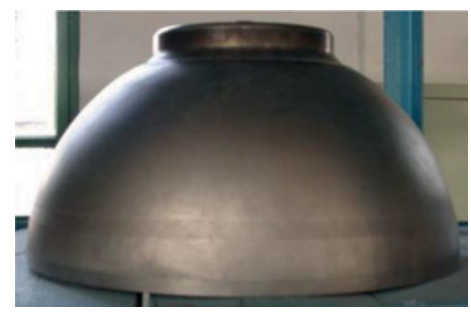

Figure 1. Half hemisphere made by SPF.

10-20\% weight savings, thus increasing the fuel efficiency and payload. It is difficult to deform Al-Li thin sheet because of its low room-temperature ductility and high notch sensitivity. SPF technology offers an effective way of forming thin-walled Al-Li components with complex shape. Investigation of superplasticity on $1420 \mathrm{Al}-\mathrm{Li}$ alloy was performed at several temperatures $\left(460^{\circ} \mathrm{C}, 480{ }^{\circ} \mathrm{C}, 500^{\circ} \mathrm{C}\right.$, $\left.520^{\circ} \mathrm{C}\right)$ and strain rates $\left(1 \times 10^{-4} \mathrm{~s}^{-1}, 5 \times 10^{-4} \mathrm{~s}^{-1}, 1 \times 10^{-3} \mathrm{~s}^{-1}, 5 \times 10^{-3} \mathrm{~s}^{-1}\right)$. Maximum elongation was $650 \%$ at $460{ }^{\circ} \mathrm{C} / 1 \times 10^{-4} \mathrm{~s}^{-1}$. The flow curve of fine-grained $1420 \mathrm{Al}$-Li alloy exhibited a stable condition at this temperature/strain rate combination. Flow stress increased with strain rate and the flow stress was $15 \mathrm{MPa}$ at $5 \times 10^{-3} \mathrm{~s}^{-1}$ strain rate. After SPF, the alloy still exhibited an equiaxed microstructure because the fine secondary phase pinned grain boundaries and prevented grain growth [9]. Tensile properties of the Al-Li alloys are listed in Table 1. The tensile strength of the $1420 \mathrm{Al}-\mathrm{Li}$ alloy after SPF decreased. It is possible that the decrease of strength was caused by grain growth and cavity formed during SPF process [10].

IN-718 (also named GH4169 in China) has great property combination at $650{ }^{\circ} \mathrm{C}$ and has a wide application in aerospace industry. A study on SPF of hot rolled GH4169 sheets was performed at BAMTRI [11]. The material exhibited equiaxed microstructure and grain size was less than $10 \mu \mathrm{m}$. An elongation of $424 \%$ has been obtained at $950{ }^{\circ} \mathrm{C} / 1 \times 10^{-3} \mathrm{~s}^{-1}$. At the temperature between $920{ }^{\circ} \mathrm{C} \sim$ $980^{\circ} \mathrm{C}$, the elongation all exceeded $300 \%$ at strain rate of $1 \times 10^{-3} \mathrm{~s}^{-1}$. There was a large increase of elongation and stress reduction when strain rate was decreased from $1.5 \times 10^{-3} \mathrm{~s}^{-1}$ to $1.0 \times 10-3 \mathrm{~s}^{-1}$.

\subsection{Application of SPF/welding}

Multi-layer hollow structures of various types can be made by SPF/DB technology. The forming difficulty is proportional to part size and complexity. The maximum part dimension has reached $3000 \mathrm{~mm} \times 1500 \mathrm{~mm}$ and the number of layers has reached four. The application of SPF/DB structures vary with part size, shape and layer number.

Single-layer SPF structure has been used as rocket fuel tanks. A fuel tank can be welded by two SPFed half hemispheres, as can be seen in Fig. 1. A larger fuel tank can be formed by adding a cylindrical section between two half hemispheres. The volume of the fuel tank varies from $80 \mathrm{~mL}$ to $800 \mathrm{~L}$ and the maximum diameter and height have reached $1100 \mathrm{~mm}$ and $1800 \mathrm{~mm}$, respectively as can be seen in Fig. 2. Wall thickness can be as low as $1.8 \mathrm{~mm}$ and thickness variation can be controlled within $0.15 \mathrm{~mm}$. Fuel tanks made by SPF/DB has significantly reduced welding work and increased structure integrity. Meantime, the lead time has also been shortened significantly.

R.X. Zhang et al. [12] used FEA to optimize the die geometry for the SPF of a Ti hemisphere. An orthogonal method was set up and FEA was used to analyze the effect of parameters on thickness 


\section{MATEC Web of Conferences}
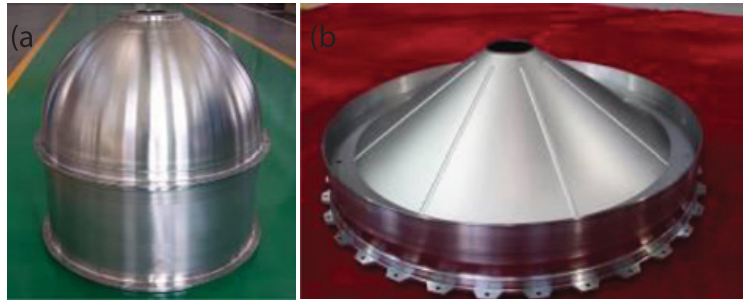

Figure 2. (a) SPF hemisphere welded with a thin-wall cylinder (b) Inner structure of a fuel tank.
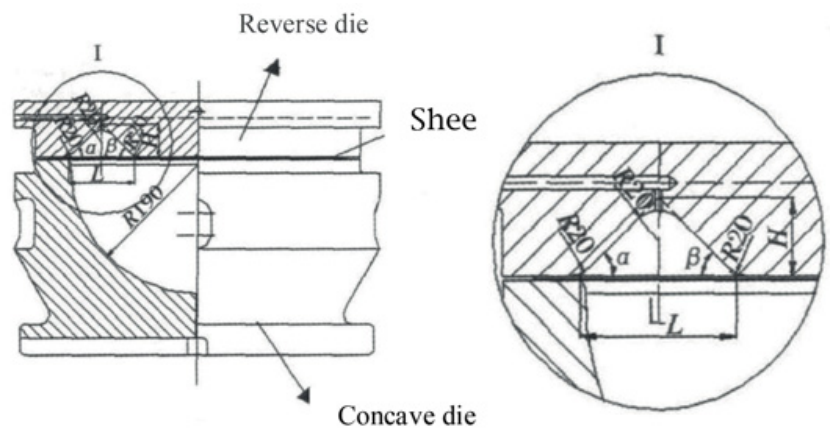

Figure 3. Profile of hemispherical component.
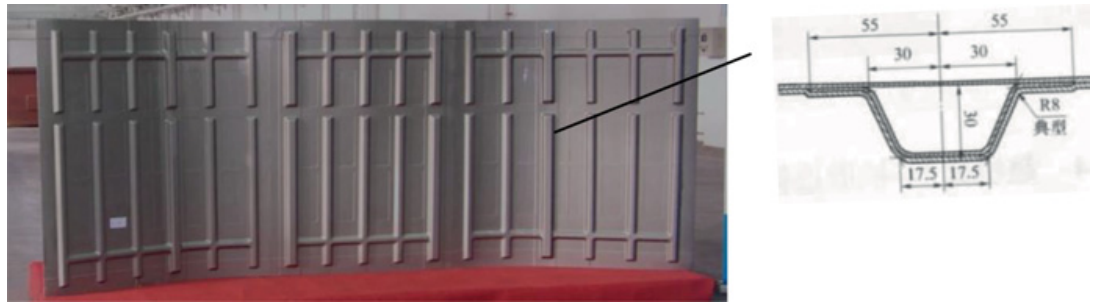

Figure 4. SPF/DB panel with strengthening ribs $(3000 \mathrm{~mm} \times 1500 \mathrm{~mm})$.

distribution of the Ti hemisphere during SPF, as can be seen in Fig. 3. Results indicate that the height of the die cavity has the largest effect on thickness distribution, followed by the die width and tip angle. The tip angle and die width affect the thinning position of Ti sheet, the larger the angle, the closer the thinning position is to the equator, while the larger the die width, the closer the thinning position is to the bottom. The thinning quantity of Ti sheet is proportional to the die height. Through FEA optimization, the die dimension is: $\mathrm{H}=40 \mathrm{~mm}, \mathrm{~L}=140 \mathrm{~mm}, \alpha=45^{\circ}$.

Panels are the main components of a fuselage, which include skin, hatch, frame, etc. In order to increase the load capacity of the panels, a lot of ribs are added. SPF/DB has found many applications in fabricating fuselage panels, hatches and frames. Figure 4 illustrates a large SPF/DB structure strengthened by ribs. It measures $3000 \mathrm{~mm} \times 1500 \mathrm{~mm}$ and weighs $55.3 \mathrm{~kg}$. This structure was laser welded together with three SPF/DB sections. Comparing with conventional processing methods, advantages include: $10 \%$ weight saving, $30 \%$ reduction of production time, $60 \%$ reduction of error rate of rework, $70 \%$ reduction of components number, $80 \%$ reduction of standard parts. 


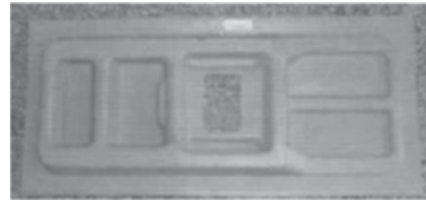

Figure 5. Ti-6Al-4V SPF/DB double-layer hatch.

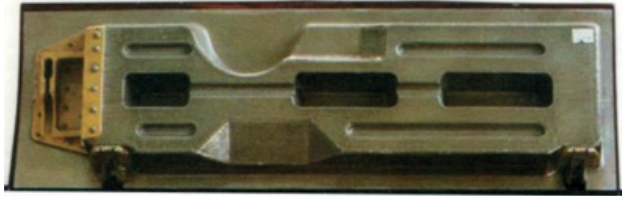

Figure 6. Ti-6Al-4V SPF/DB double-layer cabin door.

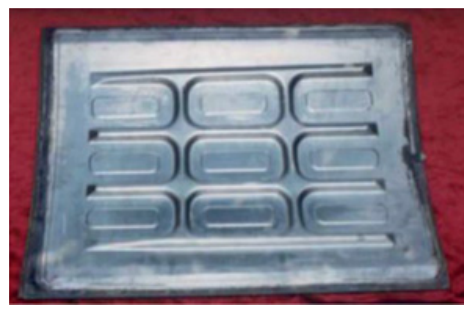

Figure 7. Ti-15V-3Al double-layer hatch.

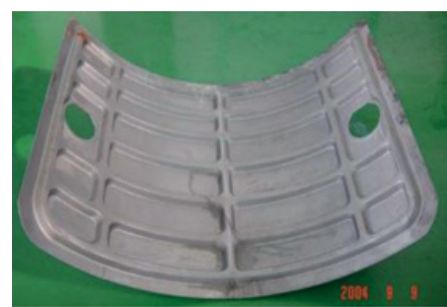

Figure 8. Maintenance hatch.

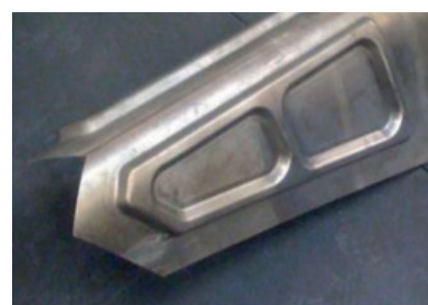

Figure 9. Fuselage panel.

Figure 5 shows a Ti-6Al-4V hatch with double-layered structure. The hatch is connected to the fuselage by bolts. The structure required a high stiffness, so a strengthening frame was added in the local area, which also increased the difficulty of SPF/DB process. The weight saving has reached $45.9 \%$ comparing with conventional processing methods. Figure 6 illustrates a cabin door made by SPF/DB. Part numbers reduced from 52 to 22 and fasteners reduced from 840 to 103 comparing with conventional processing methods. By using SPF/DB, there was a $15 \%$ weigh savings and $53 \%$ cost reduction.

Figure 7 illustrates a Ti-15V-3Al double-layer hatch made by SPF/Spot welding. The SPF temperature was $150^{\circ} \sim 200^{\circ}$ lower than that of the Ti-6Al-4V, which lowered the cost and also extend the tool life. Weight reduction of this component has reached $18.7 \%$. Another Ti-6Al-4V doublelayer structure of $1140 \mathrm{~mm} \times 940 \mathrm{~mm} \times 360 \mathrm{~mm}$ dimension is shown in Fig. 8. This structure was welded together after SPF due to the size limit. A Ti-6Al-4V saddle shaped component (Fig. 9) of $1860 \mathrm{~mm} \times 550 \mathrm{~mm}$ was made by SPF/DB. The material exhibited an equiaxed $\alpha+\beta$ microstructure and the tensile strength and elongation were above $915 \mathrm{MPa}$ and $13.7 \%$. Figure 10 and Fig. 11 show two examples of double-layered structures made by SPF/DB, the dimensions is $560 \mathrm{~mm} \times 525 \mathrm{~mm} \times$ $(0.8 \mathrm{~mm}+0.6 \mathrm{~mm})$ and $1450 \mathrm{~mm} \times 805 \mathrm{~mm} \times(0.8 \mathrm{~mm}+1.2 \mathrm{~mm})$, the weigh savings is $20.5 \%$ and $15.5 \%$, cost reduction is $55 \%$ and $20 \%$.

There are some applications of triple-layer and quadra-layer SPF/DB structures used in panels and hatches. However, wider application is limited by complexity of structure and processing. Typical application of triple-layer structure is Ti-6Al-4V wide chord fan blade which experience twisting and SPF/DB. B. Zhao [13] analyzed the hot twisting and SPF process by FEA. The effect of parameters (twisting rate, die moving speed, friction coefficient, strain rate, and core sheet thickness) on the forming process has been analyzed. Twisting rate, die moving speed, and strain rate strongly affected load and 


\section{MATEC Web of Conferences}

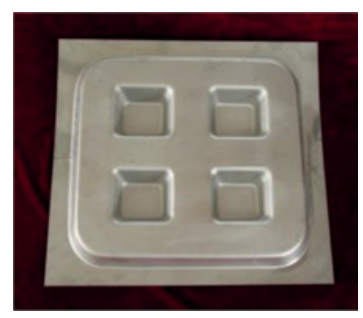

Figure 10. Double-layer hatch.

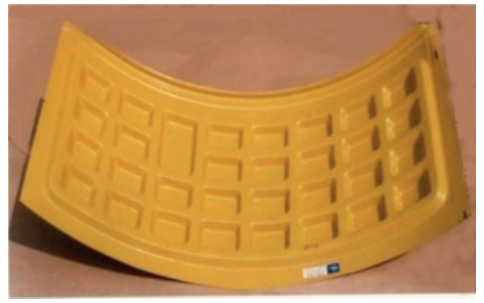

Figure 11. Double-layer fuselage hatch.

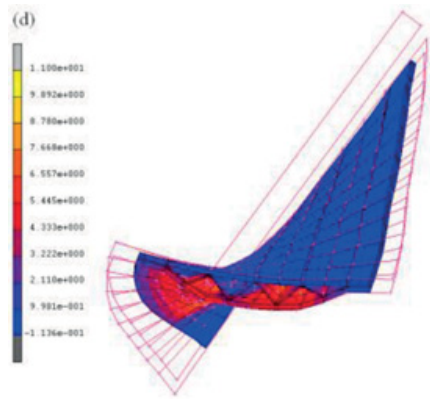

Figure 12. Equivalent Mises stress distribution.

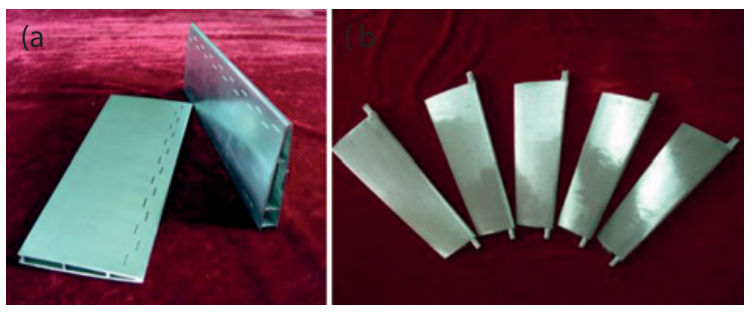

Figure 13. Ti-6Al-4V quadra-layer SPF/DB blades (a) type-1 (b) type-2.

SPF curve. Thickness of the core sheet only affected SPF curve a little and the friction coefficient of the die had little effect on forming process.

Several Ti-6Al-4V quadra-layer blades are illustrated in Fig. 13. Type-1 blade (Fig. 13a) has a dimension of $280 \mathrm{~mm} \times 90 \mathrm{~mm} \times 8 \mathrm{~mm}$ and weighs $0.3 \mathrm{~kg}$. Type- 2 blade (Fig. 13b) has a dimension of $360 \mathrm{~mm} \times 110 \mathrm{~mm} \times 16 \mathrm{~mm}$ and weighs $0.8 \mathrm{~kg}$, which is $45 \%$ lighter than a solid piece. Figure 14 is a quadra-layer structure made by SPF/DB and laser welding. The component measures $2300 \mathrm{~mm} \times$ $900 \mathrm{~mm} \times 70 \mathrm{~mm}$ and weighs $21.14-23.36 \mathrm{~kg}$.

In the casing of an engine, hollow cylindrical structures, which can be made by SPF/DB process, are usually used. Figure 5 illustrates the typical 3-layer and 4-layer SPF/DB cylinders.

$\mathrm{SPF} / \mathrm{DB}$ can be used to produce hollow structures with complex shape, but the DB process is time consuming. There are several alternatives to replace DB process, such as laser welding. Figure 16b illustrates the process of using laser welding instead of DB to join core sheets with skins to form a quadra-layer structure. This process avoided using stop-off and the time consuming DB process during which sagging of the core sheets might happen (Fig. 16a). Meantime, the total process time has reduced 


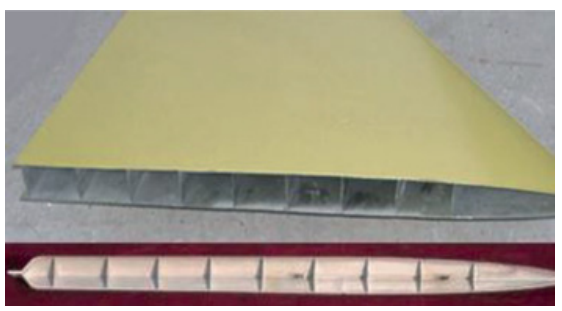

Figure 14. Ti-6Al-4V quadra-layer structure.
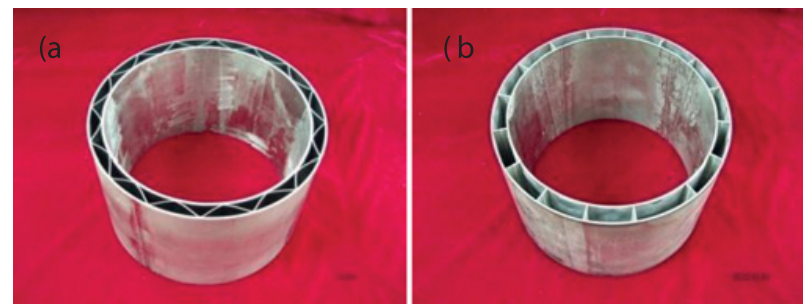

Figure 15. The SPF/DB Ti components (a) triple-layer (b) quadra-layer.

(a
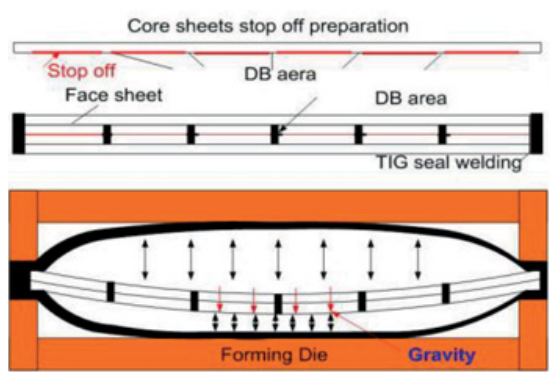

( $b$ Core sheets Laser Welds
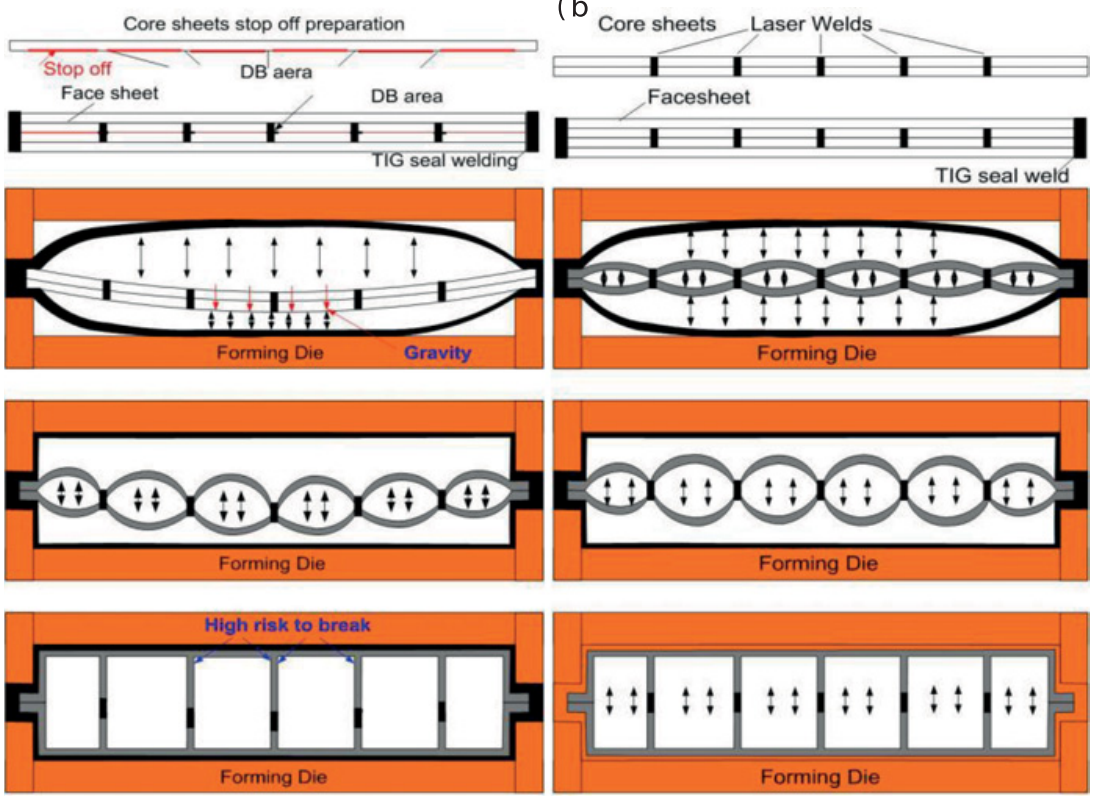

Figure 16. Comparison of DPF/DB and SPF/Laser-welding of forming a quadra-layer structure (a) SPF/DB process (b) SPF/Laser-welding process.

to $5 \mathrm{hrs}$ and this has led to a significant cost reduction for making a component. Figure 17 is one example of using SPF/Laser-welding technique to make a Ti-6Al-4V component.

Figure 18 is a corrugation beam made by SPF/HIP process. The corrugated beam was sectioned into two pieces and formed by SPF separately and HIPed together to the final shape [14]. 


\section{MATEC Web of Conferences}

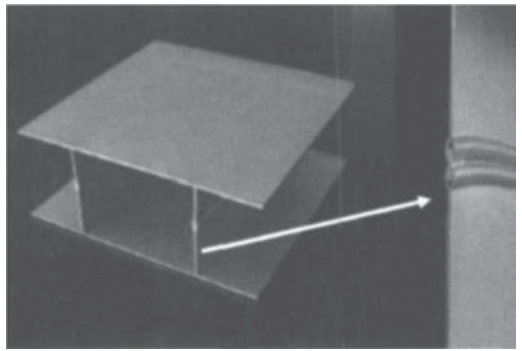

Figure 17. Ti-6Al-4V component made by SPF/Laser-welding.

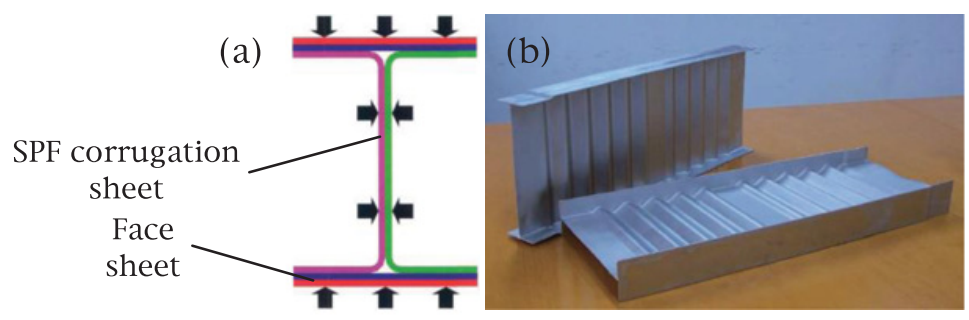

Figure 18. Corrugation beam made by SPF/HIP (a) forming process (b) component.

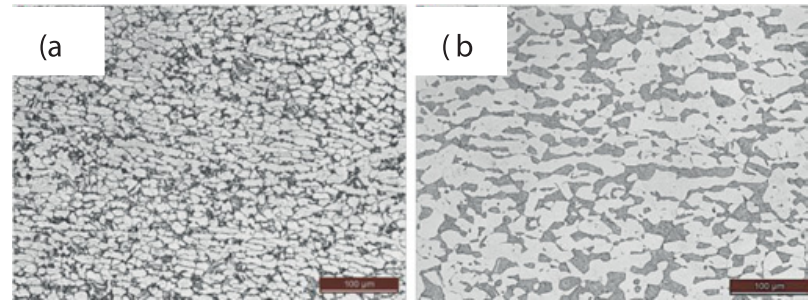

Figure 19. Microstructure of Ti-6Al-4V alloy before and after SPF/DB (a) before SPF/DB (b) after SPF/DB.

Mechanical properties of SPF/DB structure depend on four factors: structure, processing, surface strengthening, and material microstructure. A good structure design can avoid stress concentration and prevent premature failure in local area. Surface strengthening methods such as shot peening and roller burnishing introduce compressive residual stresses and improve fatigue life of components. The processing parameters of SPF/DB influence material microstructure and hence affect the mechanical properties. The microstructure of Ti-6Al-4V alloy before and after SPF/DB is shown in Figs. 19a and 19b, respectively. The as-received material exhibited an equiaxed microstructure. After several thermal cycles during SPF/DB, there was a significant coarsening of $\alpha$ phase (Fig. 19b). In general, for fatigue driven applications, smaller grains are preferred so the SPF/DB process needs to be optimized to minimize grain growth.

Ti alloys can have a pronounced anisotropy of properties, which can be directly related to the inherent anisotropy of the hexagonal crystal structure of a phase. Texture generally depends on the degree, the mode, and the temperature of deformation as well as on the subsequent annealing. The mechanical properties of Ti alloys can be strongly affected by texture. Figure 20 shows an EBSD inverse pole figure of a Ti-6Al-4V tube before (Figs. 20a and b) and after (Figs. 20c and d) SPF/DB. The colored 

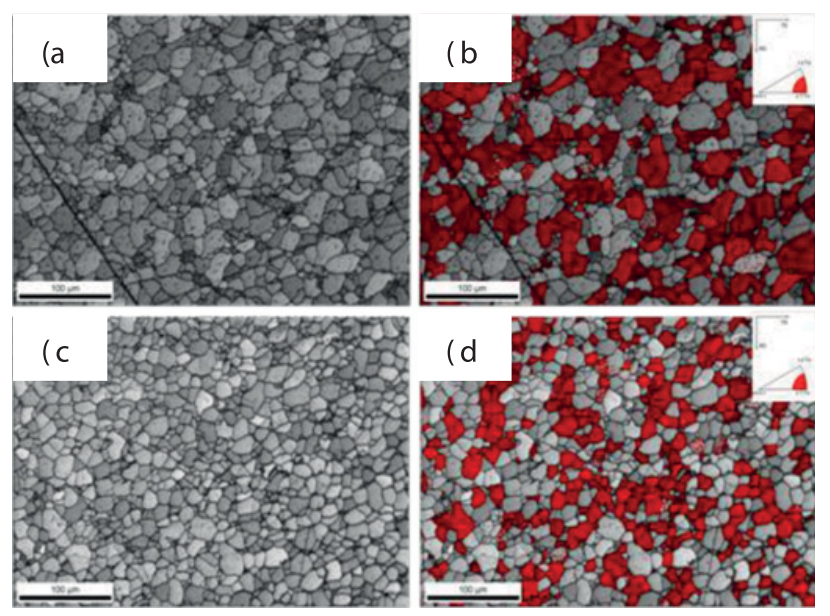

Figure 20. Microstructure and EBSD inverse pole figure of a Ti-6Al-4V tube before (a), (b) and after (c), (d) SPF/DB.

grains are oriented within $20^{\circ}$ around $\langle 2-1-10\rangle$ axis. It can be seen that the texture is almost the same before and after the $920^{\circ} \mathrm{C}$ thermal cycle.

\subsection{Progress in SPF/DB technology}

\subsubsection{D lattice structure by SPFIDB}

Metal 3D lattice structure are high-strength and light-weight structures that have been developing during the past 10 years. They are similar to 3D grids used in buildings but with a smaller size. Metal 3D lattice structure not only exhibit decent mechanical properties, the hollow area inside also provides space for integrating more functions, such as air and water circulation. It is reported that the efficiency of heat conduction for metal 3D lattice structure is 6 times higher than the regular tunnels. Metal 3D lattice is considered to be the next generation high strength, light weight structure [15].

Typical methods of fabricating 3D lattice structures include investment casting, net punching/ brazing, steel net folding/brazing, 3D weaving, additive manufacturing, extrusion line cutting and lap assembling. Comparing with these typical methods, SPF/DB process is more flexible and designable. $\mathrm{Li}$ et al. [16-18] introduced this technology to fabricate high-strength and light-weight hollow structures. SPF/DB structures can be considered as a triple-layer component. The core sheet is a grided hollow structure and the stop-off position are illustrated in Fig. 21a. The forming process is illustrated in Fig. 21b. By changing the core sheet structure and stop-off position, SPF/DB can be used to fabricate different types of 3D lattice structures, such as pyramidal, tetrahedral, and X shapes. Figure 22 illustrates several 3D lattice structures made by Ti alloys. The compression testing results showed that 3D lattice strucutre has excellent mechanical propeties the compression strength can be tailored in the range of $1 \mathrm{MPa}$ to $15 \mathrm{MPa}$. SPF/DB technology can be used to fabricate various high-strength and light-weight hollow structures, such as honeycone, porous or hybrid shapes (Fig. 23).

\subsubsection{Melting droplet spreading/thermo-mechanical forming (MDS/TMF)}

Aircrafts and aero-engines contain thousands of light-weight metal components. Additive manufacturing (AM) using high power beam such as laser and electron beam has found wide applications in aerospace industry. Typical AM technology includes Selective Electron Beam Melting 

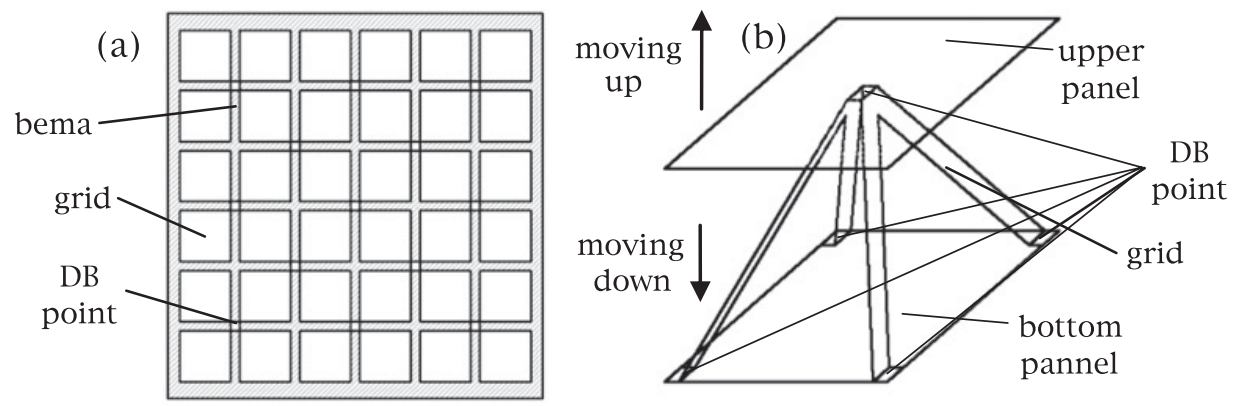

Figure 21. (a) The stop-off figure on the core sheet of pyramidal lattice structure and (b) the principle of SPF/DB process fabricating three dimensional lattice structure.

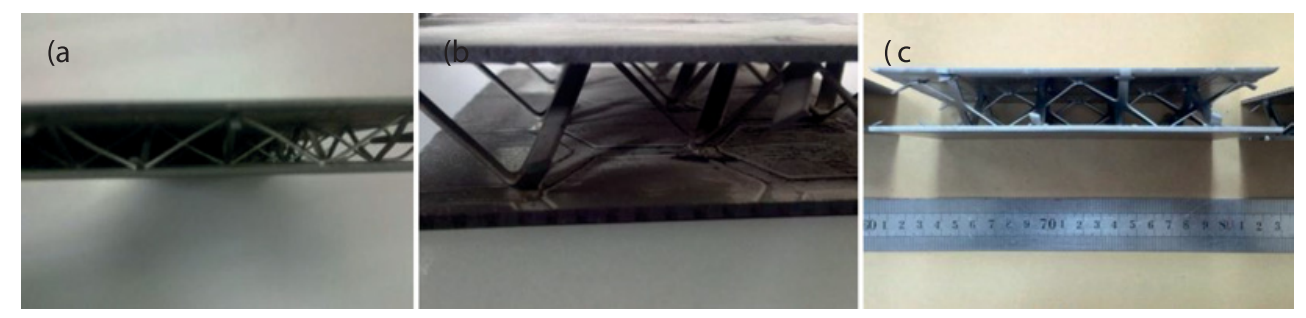

Figure 22. Three dimensional lattice structure fabricated by SPF/DB (a) pyramid type (b) tetrahedron type (c) $\mathrm{x}$-type.
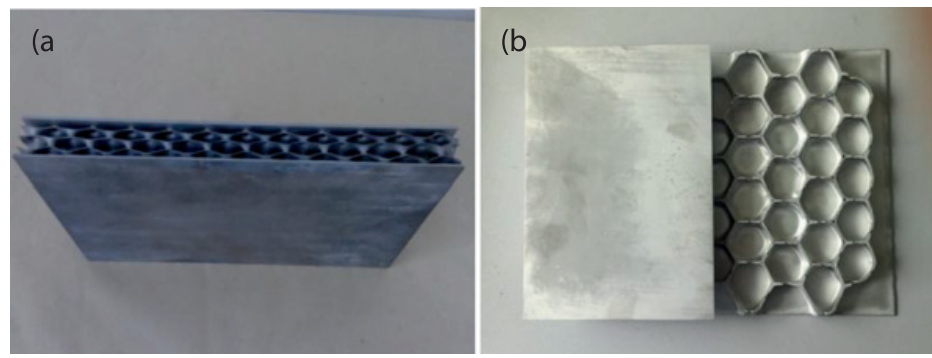

Figure 23. The multi-layer egg-box and honeycomb structure fabricated by SPF/DB (a) multi-layer egg-box structure (b) honeycomb structure.

(SEBM), Electron Beam Freeform Fabrication (EBFF), Selective laser melting (SLM), and Laser Engineered Net Shaping (LENS) [19]. Taking Ti alloys as an example, the AM material exhibits a rapid solidification microstructure and the grains are finer than the cast material. For the applications which need high fatigue strength and high damage tolerence, this kind of microstructure is not as good as the forged material which has a duplex or equiaxed microstructure.

In order to improve the mechanical properties of AM materials, BAMTRI has developed melting droplet spreading/thermo-mechanical forming (MDS/TMF) technology. The basic idea is performing mechanical processing immediately after melting droplet spreading. The mechanical processing can be rolling, friction stirring or forging, etc. (Fig. 24). Figure 25 illustrates the microstructure of Ti-6Al$4 \mathrm{~V}$ alloy at different stages. The as-spread Ti-6Al-4V exhibits a typical lamellar microstructure. The lamellar length and width range from $10 \mu \mathrm{m} \sim 100 \mu \mathrm{m}$ and $2 \mu \mathrm{m} \sim 4 \mu \mathrm{m}$, respectively. After friction 
ICNFT 2015

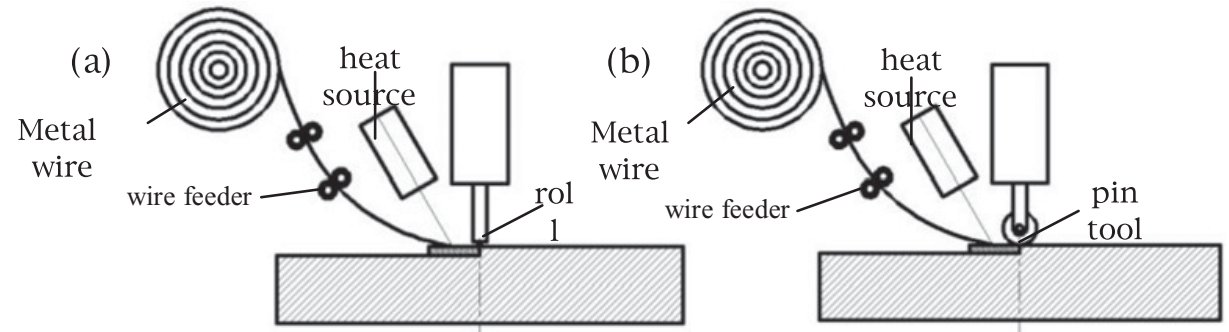

Figure 24. The principle of melting droplet spreading/thermo-mechanical forming (a) melting droplet spreading/rolling (b) melting droplet spreading/friction stir forming.
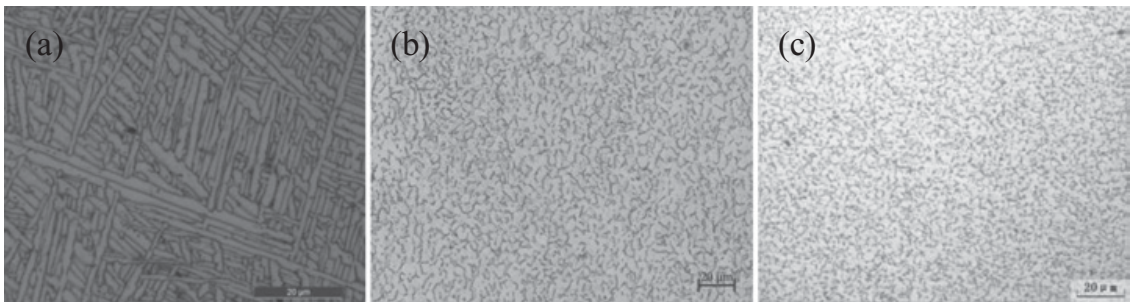

Figure 25. The microstructure of Ti6Al4V titanium alloy (a) after melting droplet spreading (b) melting droplet spreading/rolling sheet at $900^{\circ} \mathrm{C}, 950^{\circ} \mathrm{C} / 0.5 \mathrm{~h}$, furnace cooling to $590^{\circ} \mathrm{C}$, air cooling to $\mathrm{RM}$ (c) melting droplet spreading/friction stir forming: $300 \mathrm{rad} / \mathrm{min}, 60 \mathrm{~mm} / \mathrm{min}, 800^{\circ} \mathrm{C} / 2 \mathrm{~h}$, air cooling to RM.

stirring, the microstructure transformed to equiaxed grains ranging from $1 \mu \mathrm{m} \sim 5 \mu \mathrm{m}$. Preliminary results show that the tensile strength of the $800^{\circ} \mathrm{C} / 2 \mathrm{~h} / \mathrm{AC}$ annealed material reached $1065 \mathrm{MPa}$.

MDS/TMF integrates several processing steps in one machine and can be used to fabricate components of desired microstructure. It offers an option for the manufacturing metal components in aerospace industry. MDS/TMF offers a possible solution to fabricate fine grains sheet for SPF and it has more advantages for low-ductility materials.

\section{Future development of SPF}

The authors suggest five aspects regarding to the future development of SPF technology:

1. The manufacturing of light-weight structures is a process of integrating design, manufacture and qualification. First, the design team set up property requirement such as aerodynamic shape for the product. Then, the production team initiates the internal structure design and manufacturing according to the SPF/DB processing parameters. In optimization of SPF/DB structure, numerical methods are used to simulate stress, strain and thickness distribution. The processing parameters are set up accordingly and risks during processing are predicted and avoided. In addition, numerical methods are also used to calculate grid size, layout, and position in order to meet the requirement of strength, stiffness and mass distribution. Finally, the components are tested and the relationship between microstructure and processing parameters are set up based on failure analysis. Optimization of processing parameters is performed accordingly. This "designmanufacture-qualification" process has proved effective in the product development process. 


\section{MATEC Web of Conferences}

Components made through this process have good workability and controllability. The future development of CAE and CAE includes the simulation of SPF/DB forming process, prediction of life-long properties, and the optimization of structural parameters. These will have a large impact on the application of SPF/DB structures in aerospace industry.

2. Finding ways of combining SPF/DB with other joining technologies is necessary. SPF/DB can be combined with other joining technologies such as laser welding, friction stir welding, HIPping, and brazing to solve the problems in making large/complex structures. Especially for those materials which are difficult to diffusion bond or superplastically formed (high temperature Ti alloys, Ti-based intermetallics, and $\mathrm{Al}$ alloys), the hybrid processing has more advantages. For $\mathrm{Al}$ alloys, it is difficult to form hollow structure by SPF/DB because of the thick oxide on surface. This problem can be solved by using other joining technologies such as laser welding.

3. Reducing SPF/DB temperature has many advantages such as energy saving, longer tool life and short lead time. Typical methods for obtaining low temperature superplasticity include severe plastic deforming, hydrogenating, and adding high-diffusivity elements. Melting droplet spreading/thermo-mechanical forming technology offers a possible solution to fabricate fine grains sheet for SPF and it has more advantages for low-ductility materials.

4. 3D lattice structures are one direction for the future development of structural-functional components. SPF/DB is used to fabricate 3D mesh structures and multi-layer eggshell structures. The structures can be designed and optimized according to the requirement of service conditions. Comparing with regular SPF/DB multi-layer structures, 3D mesh structures are isotropic, and the hollow area inside provides large space for integrating more functions. Therefore, 3D lattice structures and multi-layer egg-box structures represent the development of light, strong and multifunctional structures and their applications are very promising in aerospace industry.

5. NDT methods are critical to the future development of SPF/DB structures. In SPF/DB hollow structures, stress concentration area such as DB joints and defects are prone to be the crack initiation sites under various loads during service. Evaluating defects and structure integrity is key to oversee the operating condition of components in service. When defects formed, how to repair and extend the life of the components is also important to reduce the maintenance cost of aerospace components. Both NDT and repairing technologies are valuable for the future development of SPF/DB structures.

\section{References}

[1] Z.Q. Li, H.P. Guo., Aeronautical Manufacturing Technology 8, 34 (2010)

[2] X.H. Zhang, Q. Shan, et al., China material progress 30, 28 (2011)

[3] H.J. Lv, C.G. Yao, et al., Mechanical engineering materials 27, 15 (2003)

[4] C. Li, et al., Rare metal materials and Engineering 41, 1400 (2012)

[5] F.S. Qi, Z. Lu, et al., Materials engineering 4, 1 (2011)

[6] K. Han, H.L. Hou, Y.Q. Wang, Journal of plasticity engineering 17, 32 (2010)

[7] K. Han, H.L. Hou, et al., Chinese Journal of rare metals 35, 475 (2011)

[8] B. Zhao et al., Materials Science Forum 189, 551 (2007)

[9] Y.L. Zhang, H.P. Guo, et al., Journal of plasticity engineering 16, 134 (2009)

[10] Y.L. Zhang, et al., Aeronautical Manufacturing Technology 10, 90 (2009)

[11] H.Y. Xu, Z.Q. Li, et al., Aeronautical Manufacturing Technology z1, 445 (2007)

[12] R.X. Zhang, W. Wu, et al., Journal of Plasticity Engineering 15, 168 (2008)

[13] B. Zhao, Z.Q. Li, et al., Rare metal materials and engineering 39, 963 (2010)

[14] X.H. Li, X.Q. Han, J. Shao, Process Research on SPF/DB for Titanium Alloy Laminated Beam 16, $50(2011)$

[15] N.A. Fleck, V.S. Deshpande, M.F. Ashby. Proc R Soc A 466, 2495 (2010) 


\section{ICNFT 2015}

[16] Z.Q. Li, B. Zhao. A fabrication method of $X$ type titanium alloy three dimensional lattice sandwich strucutre [P]. China: 201210475547.8, 2013

[17] Z.Q. Li, B. Zhao, H.L. Hou, et al., A fabrication method of supperalloy three dimensional lattice sandwich strucutre [P]. China: 201310594990.1, 2014

[18] Z.Q. Li, B. Zhao, H.L. Hou, et al. A fabrication method of titanium alloy three dimensional lattice sandwich strucutre [P]. China: 201210477451.5, 2013

[19] S.L. Gong, H.B. Suo, H.X. Li,et al. Aeronautical Manufacturing Technology 13, 66 (2013) 